\title{
Uso da adubação orgânica e cobertura morta na cultura da calêndula (Calendula officinalis L.)
}

\author{
ARAÚJO, C.B.O.; SANTOS, A.M.; FERNANDES, L.A.*; MARTINS, E.R.; SAMPAIO, R.A.; COSTA, C.A.; LEITE, \\ G.L.D. \\ Instituto de Ciências Agrárias - Universidade Federal de Minas Gerais - Av. Osmane Barbosa, s/n, Caixa Postal \\ 135 - Montes Claros/MG - CEP: 39404-006. *larnaldo@nca.ufmg.br.
}

\begin{abstract}
RESUMO: A calêndula representa fonte alternativa econômica principalmente para a agricultura familiar. O objetivo do presente trabalho foi avaliar os efeitos da adubação orgânica e do uso da cobertura morta sobre a produção de biomassa e teor de flavonóides totais em plantas de calêndula. O experimento foi realizado no Campus de Montes Claros da Universidade Federal de Minas Gerais, utilizando-se o delineamento em blocos casualizados em esquema fatorial $2 \times 2 \times 4 \mathrm{com}$ quatro repetições: duas épocas de colheita, presença ou ausência de cobertura morta e quatro doses de composto orgânico $\left(0,30,60\right.$ e $\left.90 \mathrm{t} \mathrm{ha}^{-1}\right)$. As maiores produções de biomassa e flavonóides totais foram verificadas com o aumento das doses de composto orgânico. Para os flavonóides totais o maior teor foi obtido na segunda colheita na presença de cobertura morta.
\end{abstract}

Palavras-chave: Calendula, nutrição de plantas, plantas medicinais, flavonóides

\begin{abstract}
Use of organic fertilization and mulching in the production of calendula (Calendula officinalis L.). Calendula represents an alternative economic source, mainly to familiar agriculture. The aim of this work was to study the effects of organic fertilization and mulching on phytomass production and total flavonoid content in calendula plants. The experiment was carried out at Federal University of Minas Gerais, Montes Claros Campus. The experimental design was in randomized blocks, in $2 \times 2 \times 4$ factorial arrangement, with four replicates: two harvest periods, presence or absence of mulching, and four levels of organic fertilizer $\left(0,30,60\right.$ and $\left.90 \mathrm{tha}^{-1}\right)$. The highest phytomass and total flavonoid productions were obtained with increasing levels of organic fertilizer. The highest total flavonoid content was obtained in the second harvest in the presence of mulching.
\end{abstract}

Key words: Calendula, plant nutrition, medicinal plants, flavonoids

\section{INTRODUÇÃO}

O mercado internacional de produtos de plantas medicinais está em expansão há duas décadas e ainda não existem sinais de enfraquecimento. Estimativas citadas por Ferreira (1997), apontam para um mercado mundial de 12,4 bilhões de dólares, representando cerca de $5 \%$ do faturamento do mercado mundial de produtos farmacêuticos em 1994. O Brasil apresenta grande potencial para participação expressiva nesta fatia de mercado que cresce ano a ano. Porém, o conhecimento das exigências nutricionais e aspectos relacionados à produção de matéria-prima em quantidade e qualidade devem ser mais bem estudados estabelecendo uma base de atuação nacional forte, alicerçada em pesquisas científicas que facilitará a posterior busca de mercados internacionais.

A calêndula (Calendula officinalis L.) também conhecida como mal-me-quer, maravilha, verrucária, mal-me-quer dos jardins ou margarida dourada é planta herbácea originária da Europa e aclimatada no Brasil, anual e que se multiplica exclusivamente por sementes. Os capítulos florais apresentam coloração variando do amarelo ao alaranjado sendo pouco exigente em solo, mas que necessita de boa drenagem e matéria orgânica (Martins et al., 1994).

Os capítulos florais são fontes de flavonóides (metabólitos secundários) de grande importância para a fitoterapia, possuindo ações terapêuticas, como

Recebido para publicação em 18/11/2006

Aceito para publicação em 10/06/2009

Rev. Bras. PI. Med., Botucatu, v.11, n.2, p.117-123, 2009. 
cicatrizante, antisséptica, sudorífica, colagoga, antiinflamatória, antiviral, antiemética, vasodilatadora e tonificante da pele (Montanari Júnior et al., 2000). Segundo Piccaglia (1997), o teor de flavonóides totais em calêndula varia entre 0,28 e $0,75 \%$ na inflorescência completa, além disso, destaca-se na produção de $\beta$-caroteno.

Estudos sobre aspectos agronômicos da calêndula no Brasil são muito escassos, apesar de ser uma alternativa para a rotação de culturas e como fonte de renda para os proprietários de pequenas áreas. Dentre as necessidades primárias de estudo, tem-se a adubação mineral e/ou orgânica, as quais podem contribuir para uma maior produção de biomassa e metabólitos secundários. Em geral, recomenda-se o uso de 20 a $50 \mathrm{t} \mathrm{ha}^{-1}$ de esterco de curral curtido ou composto orgânico ou $25 \mathrm{t} \mathrm{ha}^{-1} \mathrm{de}$ esterco de aves (Maia \& Furlani, 1996).

Montanari Júnior et al. (2000) relatam que a calêndula é pouco exigente em solos, mas necessita de alto teor de matéria orgânica. A adubação recomendada por este autor é de $25 \mathrm{t} \mathrm{ha}^{-1}$ de esterco bovino, 80 a $100 \mathrm{~kg} \mathrm{ha}^{-1}$ de N, $44 \mathrm{~kg} \mathrm{ha}^{-1}$ de P e 149 $\mathrm{kg} \mathrm{ha}^{-1}$ de K. Vieira et al. (1999) verificaram maiores produções de matéria fresca e de matéria seca de capítulos com uso de 14 t ha-1 $^{-1}$ de cama-de-aviário.

A calêndula pode ser cultivada durante todo ano, porém, desenvolve-se e produz melhor no inverno, sendo resistente a geadas leves. Pode ser propagada de duas formas: semeada em canteiros e transplantada, ou mesmo em semeadura direta (Montanari Júnior et al., 2000). Segundo Ming (1992), tanto fatores externos como temperatura, pluviosidade, vento, solo latitude e altitude, quanto técnicos como forma de plantio, adubação, tratos culturais e época de colheita, interferem na produção de biomassa e teor de princípios ativos das plantas.

Em relação aos efeitos da matéria orgânica, têm-se verificado que as substâncias húmicas de baixa massa molecular, além de alterarem as propriedades físicas e químicas do solo, podem ser absorvidas pelas plantas (Canellas et al., 2002). A utilização de palhas para a cobertura do solo, além de proteger as flores do contato direto com solo no caso da calêndula, pode alterar as propriedades físicas e químicas do solo a longo prazo devido a sua decomposição mais lenta, uma vez que não é incorporada imediatamente ao solo e, geralmente possui altas relações carbono/nutrientes (Kiehl, 1985).

O presente trabalho teve como objetivo estudar o efeito de diferentes doses de composto orgânico aplicado ao solo de cultivo e a presença de cobertura morta (palha de capim braquiária) sobre a produção de capítulos florais e teor de flavonóides produzidos por plantas de calêndula em duas épocas de colheita.

\section{MATERIAL E MÉTODO}

O experimento foi realizado no Horto Medicinal do Instituto de Ciências Agrárias da Universidade Federal de Minas Gerais, em Montes Claros, região Norte do Estado de Minas Gerais, no período de março a setembro de 2001. Durante o período experimental a temperatura variou de 21 a $24^{\circ} \mathrm{C}$ e a precipitação pluviométrica foi de $250 \mathrm{~mm}$.

O solo utilizado foi classificado como Argiloso vermelho-amarelo, originalmente sob vegetação de Cerrado, cujas características químicas e físicas, determinadas conforme Embrapa (1997), na camada de 0 - $20 \mathrm{~cm}$ de profundidade, foram: $\mathrm{pH}$ em água $=$ 4,$8 ; \mathrm{K}=10 \mathrm{mmol}_{\mathrm{c}} \mathrm{dm}^{-3} ; \mathrm{Ca}=8 \mathrm{mmol}_{\mathrm{cm}} \mathrm{dm}^{-3} \mathrm{Mg}=3$ $\mathrm{mmol}_{\mathrm{c}} \mathrm{dm}^{-3} ; \mathrm{Al}=20 \mathrm{mmol}_{\mathrm{c}} \mathrm{dm}^{-3} ; \mathrm{SB}=21 \mathrm{mmol}_{\mathrm{c}} \mathrm{dm}^{-3}$; $\mathrm{T}=48 \mathrm{mmol}_{\mathrm{c}} \mathrm{dm}^{-3} ; \mathrm{V}=33 \%$; MOS $=18 \mathrm{~g} \mathrm{~kg}^{-1}$; areia $=800 \mathrm{~g} \mathrm{~kg}^{-1} ;$ silte $=120 \mathrm{~g} \mathrm{~kg}^{-1}$; argila $=80 \mathrm{~g} \mathrm{~kg}^{-1}$. O delineamento experimental foi de blocos casualizados no esquema fatorial $2 \times 2 \times 4$ com 4 repetições - duas épocas de colheita, com e sem cobertura morta e quatro doses de composto orgânico incorporado ao solo nas dosagens de $0,30,60$ e $90 \mathrm{t} \mathrm{ha}^{-1}$.

Oito semanas antes do plantio das mudas de calêndula no campo foi realizada uma aração e duas gradagens em toda a área experimental e incorporou-se na camada de $0-20 \mathrm{~cm}$ de profundidade o equivalente a 1,8 tha-1 de calcário dolomítico (PRNT $=100 \%$ ) para elevar a saturação por bases do solo para $70 \%$, conforme recomendado por Ribeiro et al. (1999), para floricultura e jardins.

Quatro semanas após a calagem foram incorporados na camada de 0 - $10 \mathrm{~cm}$ de profundidade, $600 \mathrm{~kg} \mathrm{ha}^{-1}$ do adubo 4-30-10, que equivaleu à adição de $24 \mathrm{~kg} \mathrm{ha}^{-1}$ de $\mathrm{N}, 79 \mathrm{~kg} \mathrm{ha}^{-1}$ de P e $50 \mathrm{~kg} \mathrm{ha}^{-1}$ de K. Nessa oportunidade, após a incorporação do fertilizante mineral, delimitaram-se as parcelas experimentais e construíram-se os canteiros com as seguintes dimensões: 1,4 m de largura, $2 \mathrm{~m}$ de comprimento e $0,2 \mathrm{~m}$ de altura. As parcelas experimentais foram distanciadas em 0,5 m entre si. Em seguida, incorporaram-se as respectivas doses de composto orgânico na camada de 0 - $10 \mathrm{~cm}$ de profundidade.

O composto orgânico utilizado foi obtido a partir de resíduos vegetais e esterco bovino. O tempo de compostagem foi de 72 dias, em condições adequadas de temperatura e umidade da massa de compostagem. No final do processo de compostagem, o material apresentou a seguinte composição, conforme determinação analítica proposta por Kiehl (1985): $185,0 \mathrm{~g} \mathrm{~kg}^{-1}$ de carbono orgânico; $11,2 \mathrm{~g} \mathrm{~kg}^{-1}$ de $\mathrm{N}$ total; 16,5 de relação $\mathrm{C} / \mathrm{N} ; 2,2 \mathrm{~g} \mathrm{~kg}^{-1}$ de $\mathrm{P} ; 10,3$ $\mathrm{g} \mathrm{kg}^{-1}$ de K; 30,5 g kg-1 de Ca e 9,6 g kg-1 de Mg. Nos tratamentos onde se aplicou o composto orgânico, foram adicionados o equivalente a $336 \mathrm{~kg}$ de N, 67,3 $\mathrm{kg} P$ de e 306,3 kg de $\mathrm{K}$ na dose de $30 \mathrm{t} \mathrm{ha}^{-1} \mathrm{de}$ composto orgânico; $672 \mathrm{~kg}$ de N, $134,6 \mathrm{~kg}$ de $\mathrm{P}$ e $617,5 \mathrm{~kg}$ de $\mathrm{K}$ na dose de $60 \mathrm{t} \mathrm{ha}^{-1}$ de composto 
orgânico; 1.008 kg de N, 201,9 kg de P e 926,3 kg de $\mathrm{K}$ na dose de $90 \mathrm{t} \mathrm{ha}^{-1} \mathrm{e}$ composto orgânico. Como cobertura do solo utilizou-se palha de capim braquiária, logo após o plantio das mudas no campo. As irrigações foram realizadas mantendo-se a umidade do solo próximo a sua capacidade de campo. A partir da curva característica do solo utilizou-se de tensiômetros para o monitoramento diário da umidade do solo.

Para a produção das mudas de calêndula foram utilizadas sementes provenientes da coleção de germoplasma de plantas medicinais do Instituto de Ciências Agrárias. A semeadura foi feita em bandejas de isopor com 150 células, e após 34 dias de emergência as plantas foram levadas ao campo. Na época do plantio das mudas, em cada parcela experimental, foram coletadas amostras de solo na camada de 0 a $20 \mathrm{~cm}$ de profundidade para análise química, conforme Embrapa (1997).

Em cada parcela experimental de $2,8 \mathrm{~m}^{2}(2 \mathrm{~m}$ de comprimento por $1,4 \mathrm{~m}$ de largura) foram cultivadas 16 plantas de calêndula, no espaçamento $0,35 \mathrm{~m}$ entre plantas na linha e $0,5 \mathrm{~m}$ nas entrelinhas de plantio. Para a avaliação do estudo foram utilizadas as quatro plantas centrais de cada parcela experimental, que correspondeu a uma área útil de $1,58 \mathrm{~m}^{2}$.

A primeira época de colheita teve início no nono dia após o plantio das mudas no campo e terminou no quadragésimo quinto dia, com intervalo de coleta de 15 dias e, a segunda, iniciou-se no sexagésimo dia e terminou no nonagésimo dia após o plantio, também com coletas a cada 15 dias. Em cada colheita, foram determinadas as produções de matéria fresca e seca e o teor de flavonóides totais nos capítulos florais, segundo metodologia proposta por Santos (1998).

As variáveis estudadas foram submetidas à análise de variância e os tratamentos comparados por análise de regressão.

\section{RESULTADOE DISCUSSÃO}

Não foram verificadas diferenças estatísticas entre os tratamentos para os atributos químicos do solo (Tabela 1). Independente da dose, o composto aplicado na época de plantio das mudas de calêndula no campo, ou seja, após calcário e fertilizante mineral não foram suficientes para alterar as características químicas do solo (Tabela 1). No entanto, quando se compara as características químicas do solo antes e após a aplicação de calcário e fertilizante mineral, observa-se alteração expressiva das mesmas (Tabela 1). Dessa maneira, pode-se inferir que quantidades de nutrientes na forma mineral fornecidas via composto orgânico não foram significativas para alterar as características químicas do solo, mesmo na dose mais elevada. Destaca-se a redução expressiva nos teores de potássio trocável em relação à amostragem do solo realizada antes do cultivo. Provavelmente essa redução foi devida, principalmente, a possível lixiviação de $\mathrm{K}^{+}$dos canteiros durante o período experimental, para camadas abaixo da amostrada.

Para as variáveis, matéria fresca e matéria seca houve efeito significativo das doses de composto orgânico $(p<0,05)$.

A matéria fresca de capítulos teve um comportamento quadrático em função das doses de composto orgânico (Figura 1), sendo a maior produção, 1,49 tha-1 , obtida na dose correspondente a $67 \mathrm{t} \mathrm{ha}^{-1}$ de composto.

Quanto à produção de matéria seca, observou-se aumento linear com as doses de composto orgânico utilizado (Figura 2), sendo $0,26 \mathrm{t}$ $\mathrm{ha}^{-1}$ a produção máxima obtida na dose de $90 \mathrm{t} \mathrm{ha}^{-1}$. de composto orgânico. Vieira et al. (1999) obtiveram maior produção de matéria seca de capítulos de calêndula quando utilizaram $40 \mathrm{t} \mathrm{ha}^{-1}$ de cama de aviário. Silva et al. (2002), trabalhando com Zingiber

TABELA 1. Média dos atributos químicos do Argissolo vermelho-amarelo após aplicação de calcário, adubo mineral e composto orgânico, em função das doses de composto orgânico.

\begin{tabular}{|c|c|c|c|c|c|c|c|c|c|c|}
\hline \multirow{2}{*}{$\begin{array}{c}\text { Dose } \\
\text { Composto } \\
\text { Orgânico }\end{array}$} & \multicolumn{10}{|c|}{ Atributos químicos } \\
\hline & $P^{(1)}$ & $K^{(1)}$ & $\mathrm{Ca}^{(2)}$ & $\mathrm{Mg}^{(2)}$ & $A l^{(2)}$ & $\mathrm{H}+\mathrm{Al}^{(3)}$ & SB & $\mathrm{T}$ & V & MOS \\
\hline $\mathrm{Tha}^{-1}$ & $\mathrm{mg} \mathrm{dm}^{-3}$ & - & - & - & $--\mathrm{mn}$ & ${ }_{c} \mathrm{dm}^{-3}-$ & - & -.-- & $\%$ & $\mathrm{~g} \mathrm{~kg}^{-1}$ \\
\hline 0 & 23,5 & 4,9 & 77,1 & 17,4 & 0,0 & 12,1 & 99,4 & 111,5 & 89 & 26 \\
\hline 30 & 24,1 & 5,5 & 79,0 & 14,5 & 0,0 & 11,4 & 99,0 & 110,4 & 90 & 25 \\
\hline 60 & 22,5 & 6,0 & 82,3 & 15,8 & 0,0 & 10,5 & 104,1 & 114,6 & 91 & 27 \\
\hline 90 & 23,4 & 5,8 & 80,2 & 15,1 & 0,0 & 11,1 & 101,1 & 112,2 & 90 & 23 \\
\hline
\end{tabular}

Extratores: (1) Mehlich 1; (2) Cloreto de potássio; (3) Acetato de cálcio. 


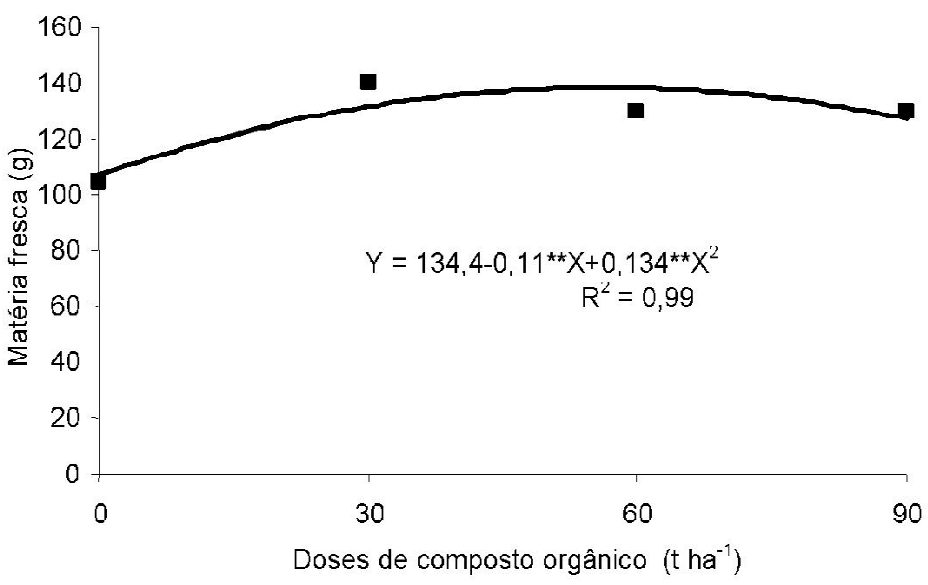

FIGURA 1. Matéria fresca de capítulos de calêndula em função das doses de composto orgânico.

officinalis L., Mattos (2000) com Mentha arvensis L. e Cruz (1999) com Mentha x villosa Huds., também verificaram aumento da produção de matéria seca com o uso exclusivo de adubos orgânico

Apesar de não terem sido observadas alterações nas características químicas do solo pela aplicação de composto orgânico (Tabela 1), pode ter ocorrido melhoria das propriedades físicas do solo, beneficiadas pela presença das substâncias húmicas de baixa massa molecular do composto orgânico, contribuindo para o aumento tanto da matéria fresca quanto da matéria seca. Segundo Canellas et al. (2002), as substâncias húmicas exercem um efeito indireto sobre o crescimento vegetal por meio do condicionamento das propriedades químicas, físicas e biológicas do solo que, via de regra, proporcionam melhores condições de cultivo. As substâncias húmicas podem atuar diretamente no metabolismo das plantas por meio de mecanismos ainda não muito claros. Segundo Nannipieri et al. (1993), as substâncias húmicas exercem influência positiva no transporte de íns, facilitando o processo de absorção; aumenta a respiração e a velocidade das reações enzimáticas do ciclo de Krebs, resultando em maior produção de energia metabólica sob a forma de ATP; aumenta o conteúdo de clorofila; aumenta a síntese de ácidos nucléicos; exerce efeito seletivo sobre a síntese protéica e, aumenta ou inibe a atividade de diversas enzimas.

Outro fator a ser considerado é a provável maior umidade do solo nos tratamentos com as maiores doses de composto orgânico, devido a maior retenção de água pela matéria orgânica. Nos tratamentos com as maiores doses de composto orgânico observou-se, pela diferença entre a massa de matéria fresca e seca (Figuras 1 e 2), maior teor de água nas plantas.

Corroborando com os resultados obtidos, Silva et al. (2002) não identificaram interação entre a cobertura morta e a adubação com esterco animal para a cultura do gengibre. Wanderer \& Barros (2002), estudando o efeito da cobertura morta da palha de trigo em plantas de melissa, verificaram que além de incremento na produção de biomassa de $21 \%$ em relação ao tratamento sem cobertura, a matéria-prima obtida foi de melhor qualidade por apresentar menos sujeiras causadas pelo contato da parte aérea da planta com o solo descoberto.

É interessante destacar a título de informação, uma vez que não era objetivo do trabalho, que no tratamento com maiores doses de composto orgânico observou-se incidência de pulgões maior que no tratamento testemunha. Leite et al. (2005) verificaram que o aumento da dose de adubo orgânico favorece a incidência de pulgões da espécie Ureleucon ambrosiae e não afeta as demais pragas.

Para os teores de flavonóides totais, houve efeito significativo $(p<0,05)$ dos tratamentos estudados. Na primeira época de colheita e ausência de cobertura morta, o maior teor de flavonóides totais, $0,58 \%$, foi obtido na dose correspondente a $59 \mathrm{t} \mathrm{ha}^{-1}$ de composto orgânico (Figura 3).

Nessa mesma época e na presença de cobertura morta, omaior teor $(0,58 \%)$ foiobtido na dose correspondente a 68 t ha $^{-1}$ de composto orgânico (Figura 4).

$\mathrm{Na}$ época 2, tanto na ausência quanto na presença de cobertura do solo, os maiores teores de flavonóides foram obtidos com a aplicação de $59 \mathrm{t} \mathrm{ha}^{-1}$ do composto orgânico, porém, na ausência de cobertura o teor máximo de flavonóides obtido foi de $0,5 \%$ (Figura 5), enquanto que na presença de cobertura foi de $0,70 \%$ (Figura 6).

Multiplicando-se a produção máxima de matéria seca, $263,1 \mathrm{t} \mathrm{ha}^{-1}$, pelos respectivos teores máximos de flavonóides totais obtidos nos diferentes tratamentos, estimou-se produção de flavonóides totais. Como não houve diferença entre os tratamentos quanto à produção de matéria seca, a produção de flavonóides totais teve o mesmo comportamento que os teores e corresponderam a 1,53; 1,32; 1,53 e 1,84 $\mathrm{kg} \mathrm{ha}^{-1}$, respectivamente para os tratamentos época 1 sem cobertura, época $1 \mathrm{com}$ cobertura, época $2 \mathrm{sem}$ cobertura e época 2 com cobertura. 


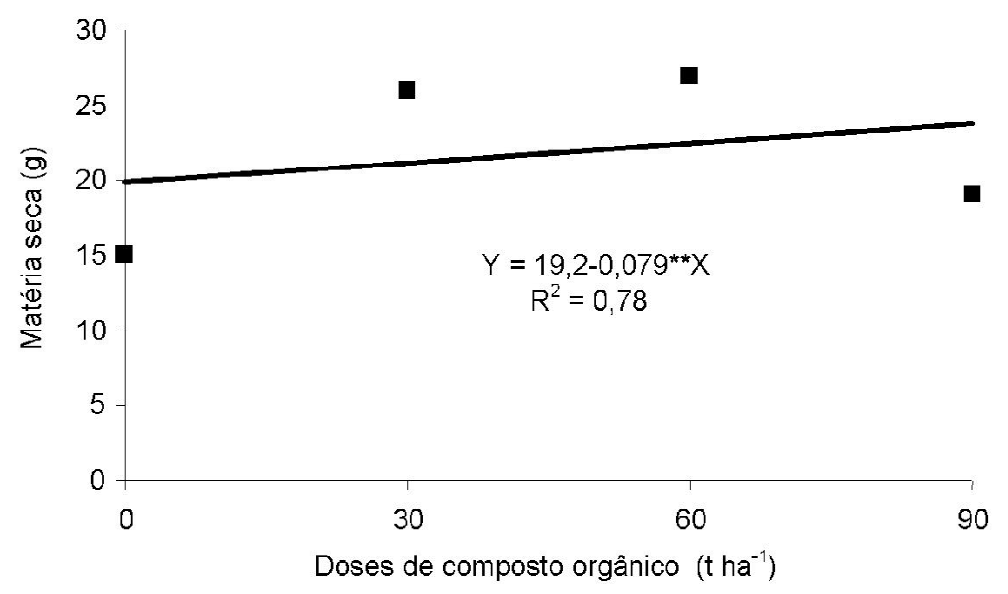

FIGURA 2. Matéria seca de capítulos de calêndula em função das doses de composto orgânico.

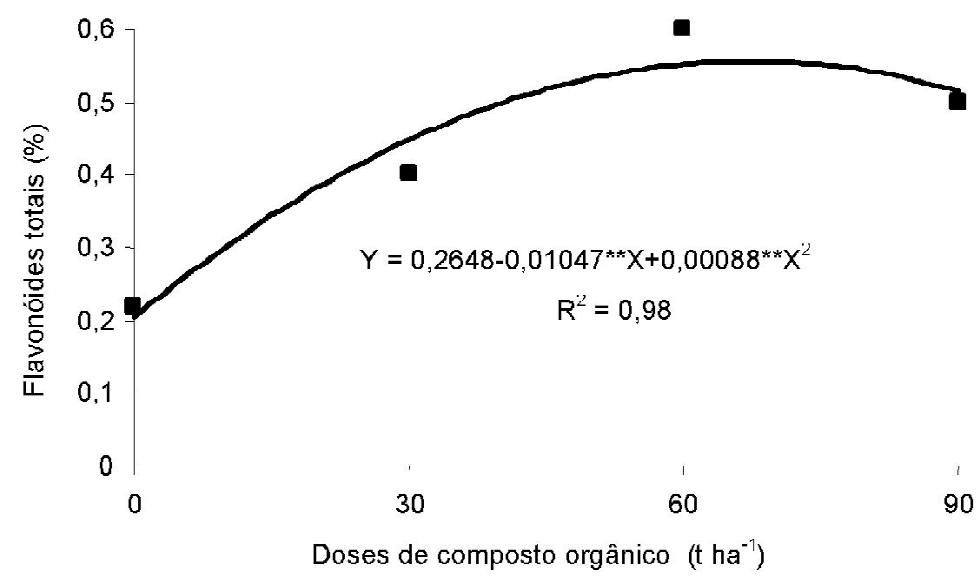

FIGURA 3. Teor de flavonóides totais de calêndula em função das doses de composto orgânico na época 1 e sem cobertura morta.

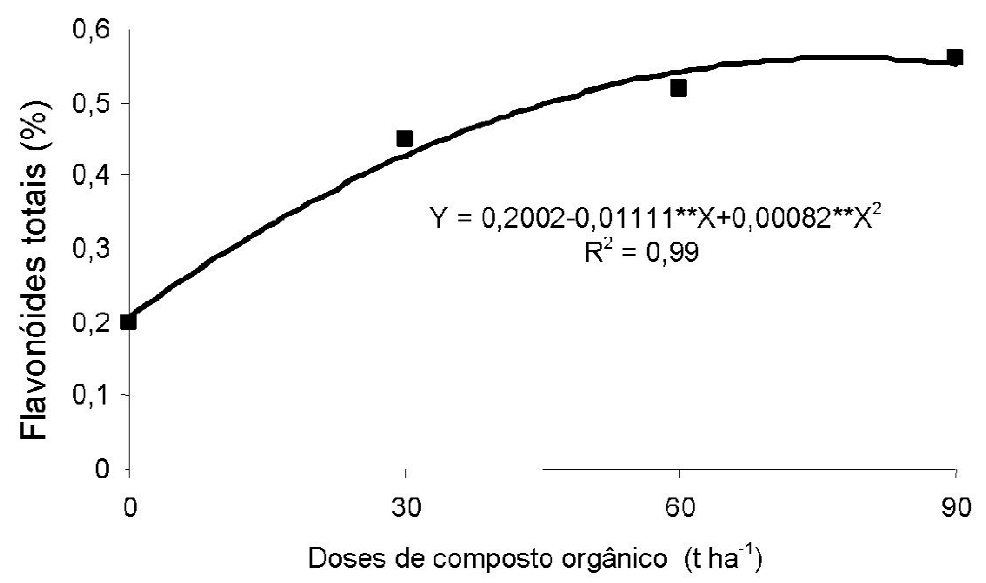

FIGURA 4. Teor de flavonóides totais de calêndula em função das doses de composto orgânico na época 1 e com cobertura.

\section{CONCLUSÃO}

As maiores produções de matéria fresca e seca de capítulos de calêndula foram obtidas na dose de 67 t ha-1 de composto orgânico;

A maior produção de flavonóides totais naépoca
1 foi obtida na dose de 59 t ha-1 $^{-1}$ de composto orgânico, na ausência de cobertura, e, na época 2, na dose de 54 t ha ${ }^{-1}$ de composto na presença de cobertura morta. 


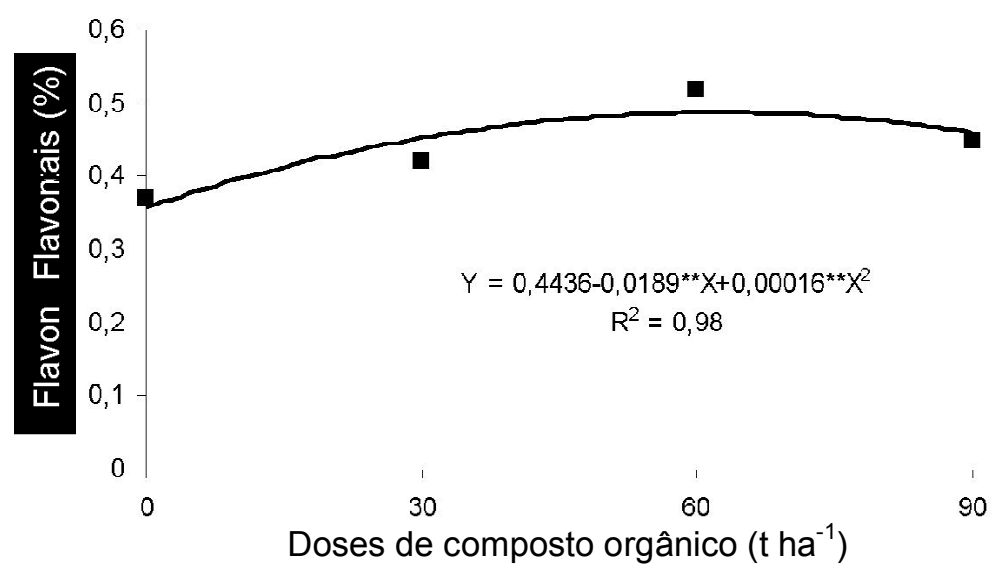

FIGURA 5. Teor de flavonóides totais de calêndula em função das doses de composto orgânico na época 2 e sem cobertura.

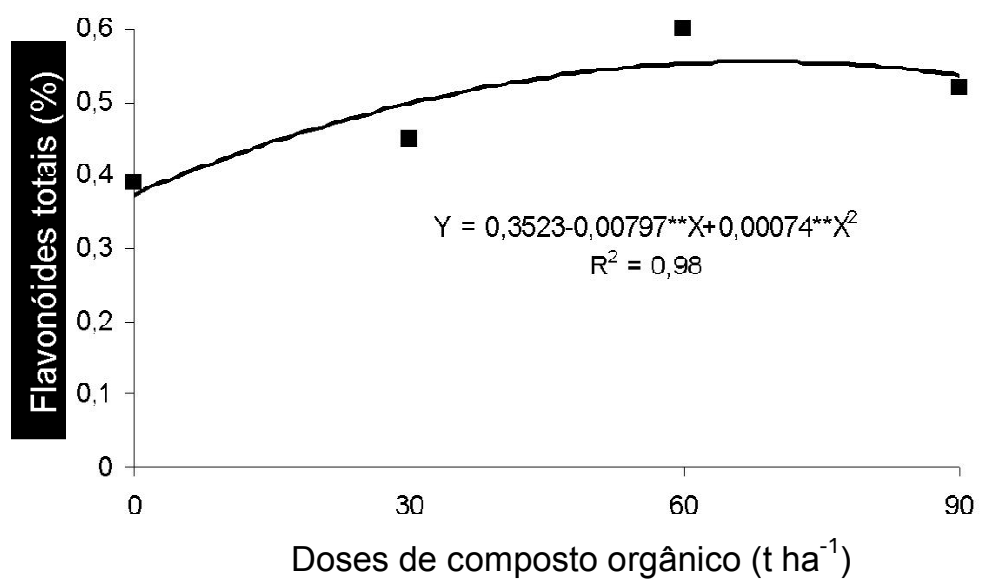

FIGURA 6. Teor de flavonóides totais em calêndula em função das doses de composto orgânico na época 2 e com cobertura.

\section{REFERÊNCIA}

CANELLAS, L.P. et al. Humic acids isolated from earthworm compost enhance root elongation, lateral root emergence, and plasma membrane $\mathrm{H}^{+}$- ATPase activity in maize roots. Plant Physiology, v.130, p.1951-7, 2002. CRUZ, G.F. Desenvolvimento de sistema de cultivo para hortelã-rasteira (Mentha $\boldsymbol{x}$ villosa Huds.). 1999. 35p. Dissertação (Mestrado - Fitotecnia) - Universidade Federal do Ceará, Fortaleza.

EMBRAPA - Empresa Brasileira de Pesquisa Agropecuária. Serviço Nacional de Levantamento e Conservação de Solo. Manual de métodos de análise de solo. Rio de Janeiro: Ministério da Agricultura, 1997. 212p.

FERREIRA, S.H. Fitoterápicos no Brasil: um diagnóstico. Campinas: Academia Brasileira de Ciências/MCT, 1997. 112p.

KIEHL, E.J. Fertilizantes orgânicos. São Paulo: Editora Agronômica Ceres, 1985. 492p.

LEITE, G.L.D. et al. Níveis de adubação orgânica na produção de calêndula e artrópodes associados. Arquivos do Instituto Biológico, v.72, n.2, p.227-33, 2005.
MAIA, N.B.; FURLANI, A.M.C. Especiarias, aromáticas e medicinais. In: RAIJ, B. et al. Recomendações de adubação e calagem para o estado de São Paulo. Campinas: IAC, 1996. p.73-90. Boletim Técnico oo 100 MARTINS, E.R. et al. Plantas medicinais. Viçosa: Universidade Federal de Viçosa, 1997. 220p.

MATTOS, S.H. Estudos fitotécnicos da Mentha arvensis L. var. piperacens Holmes como produtora de mentol no Ceará. 2000, 98p. Tese (Doutorado -Fitotecnia) Universidade Federal do Ceará, Fortaleza.

MING, L.C. Influência de diferentes níveis de adubação orgânica na produção de biomassa e teor de óleos essenciais de Lippia alba (Mill.) N.E.Br.-Verbenaceae. 1992. 206p. Dissertação (Mestrado - Produção Vegetal)Universidade Federal do Paraná, Curitiba.

MONTANARI JÚNIOR et al. Aspectos do cultivo comercial de calêndula. Campinas: Centro Pluridisciplinar de Pesquisas Químicas e Biológica Universidade Estadual de Campinas, 2000. 38p. NANNIPIERI, O. et al. Proprietá biochimichee fisiologiche della sostanza organica. In: NANNIPIERI, P. Ciclo della sostanza organica del suelo. Bologna: Pátron, 1993, p.67-78. 
PICCAGLIA, R. Effects of harvesting date and climate on the flavonoid and carotenoid contents of marigold (Calendula officinallis L.). Flavour and Fragrance Journal, v.12, p.85-90, 1997.

RIBEIRO, A.C. et al. Recomendações para uso de corretivos e fertilizantes em Minas Gerais. Viçosa: CFSEMG, 1999. 359p.

SANTOS, M.D.; BLATT, C.C.T. Teor de flavonóides e fenóis totais em folhas de Pyrostegia venusta Miers. de mata e de cerrado. Revista Brasileira de Botânica, v.21, p.1-9, 1998.

SILVA, M.A.S. et al. Efeitos da adubação orgânica e da cobertura morta na produtividade de gengibre (Zingiber officinale Rosc.). In: SIMPÓSIO DE PLANTAS MEDICINAIS DO BRASIL, 17., 2002, Cuiabá. Resumos... Cuiabá: Universidade Federal do Mato Grosso, 2002. CD-ROM. VIEIRA, M.C. et al. Crescimento e produção de capítulos de calêndula (Calendula officinallis L.), em função de cama-de-aviário semi-decomposta e de fósforo. Revista Brasileira de Plantas Medicinais, v.1, n.2, p.45-51, 1999. WANDERER, M.; BARROS, I.B.I. Rendimento de biomassa de cultivares de melissa sob diferentes coberturas de solo. In: SIMPÓSIO DE PLANTAS MEDICINAIS DO BRASIL, 17., 2002, Cuiabá. Resumos... Cuiabá: Universidade Federal do Mato Grosso, 2002. CD-ROM. 